\title{
Study on Electric Vehicles' Time - sharing Leasing in Beijing
}

\author{
Xin-Yue YAO \\ The high school affiliated to Northern Jiao tong University, \\ Beijing, China \\ zhangli628000@126.com
}

\begin{abstract}
With the environment problem and the energy crisis becoming more and more serious, the new energy vehicle industry has developed rapidly. In recent years, China's new energy vehicles achieve explosive growth driven by the policy, of which, Beijing, Shanghai, Guangzhou Shenzhen, Tianjin and other first or second-tier cities under purchase limitation become the main area of consumption of new energy vehicles. When the new energy vehicles encounter "Internet thinking" and "shared economy", new energy vehicles sharing emerges as the times require. The sharing is settled in hours or minutes. Short travel time and distance allow new energy vehicles to cleverly avoid the weakness on the endurance mileage, which can ease the traffic pressure and effectively improve the efficiency of the transport at the same time. This article will take the consumers of electric vehicles' time-sharing leasing as the research objects and carry out the research and interview to the electric vehicles' time-sharing leasing in Beijing area to get to know the basic situation of Beijing electric vehicles' timesharing leasing. And then analyze the existing problems from the consumers' points of view and put forward the corresponding solutions. It is hoped that this research will provide some suggestions for the market operation of electric cars in other areas.
\end{abstract}

\section{Keywords-electric vehicles; Time - sharing Leasing, Questionnaire}

\section{INTRODUCTION}

With the environment problem and the energy crisis becoming more and more serious, as the world's largest vehicle producer and consumer, China keeps up with the development trend, and actively responds to the serious challenges from the environment and energy, carefully arranges the development and utilization of new energies, and vigorously promotes the application of new energy vehicles demonstration. Since 2009, China has fully launched the "The project of 1000 energy-saving and new energy vehicles' demonstration and application in 10 cities" to promote the commercialization and market-oriented operation of new energy vehicles. Up to now, the new energy vehicles have been demonstrated in 89 cities and regions nationwide, and the concept of energy saving and environmental protection has gradually been accepted and recognized by consumers. In 2015, China's new energy vehicles showed an "explosive growth" under the background of a series of favorable policies. According to data released by the China Vehicle Industry Association, the production of new energy vehicles amounted to 340,471 vehicles and the sales were of 331,092 in 2015 [1-3], and the innovation of business model has injected a forward impetus for the development of new energy vehicles.

Because new energy vehicles are more expensive than traditional cars, with shorter endurance mileage, less driving experience, and imperfect charging infrastructure and other reasons, consumers are still holding the wait-and-see attitude of buying new energy vehicles. The promotion and marketing of new energy vehicles in China are facing bottlenecks. And the sharing concept of time-sharing leasing combined with the "Internet $+"$ came into being, and it applies pure electric vehicles as the main model.

In recent years, in order to allow more people to experience the superiority of new energy vehicles, new energy vehicles' time-sharing leasing companies then emerged in China. EVCARD appeared in the public in 2013, whose economic benefits, the advantages of energy saving and environmental protection attract a large number of consumers to choose EVCARD in their daily travel. Up to now, EVCARD has been successfully promoted in 23 cities and has invested more than 7500 new energy vehicles. In Beijing, because the local government's lottery policy for fuel vehicles limits the opportunities for some people to buy a car, more and more people choose to rent the new energy vehicles as a daily travel tool. According to statistics, GreenGo, Yiyi zuche, Yidu yongche and other ten more kinds of new energy time-sharing rental platform appeared in Beijing, of which the GreenGo of larger scale basically covers the Beijing urban area and the leasing station are up to 57.From the perspective of leasing enterprises, timesharing leasing integrates effective resources of society, utilizes intelligent system, lowers manpower cost and promotes market promotion. As an innovative business model, time-sharing leasing reduces the cost to use by $80 \%$ compared with traditional cars, and increases the utilization rate of electric vehicles by 2 3 times. [6].

This paper focuses on the new energy time-sharing leasing model of the leasing companies in Beijing, and goes deep into the leasing sites, objectively reflecting the business 
model level of the time-sharing leasing of electric vehicles.

\section{METHOD}

Through the data inquiry, the electric vehicles' timesharing leasing in Beijing are mainly the GreenGo, Capital car GoFun, Leshare and other brands.

First of all, the electric vehicles' time-sharing leasing users were interviewed, mainly conduct in-depth exchanges from the convenience of vehicle use, problems of charging, technical support of operators, the rationality of the rental price and other aspects. Through interviews we get to know the real experience of leasing users for electric cars' leasing more systematically, more comprehensively collect the information of vehicle use of time-sharing leasing brands, operators, trading methods and other aspects, and get more information about vehicles, operators, and transactions.

On the basis of referring to the academic research results of domestic and foreign scholars, the questionnaire was designed according to the specific circumstances of the electric vehicle time-sharing leasing. Then, through the test, repeated discussions and modifications, the questionnaire was finally determined. This paper makes a questionnaire survey on the rental users of 32 electric car rental outlets in Chaoyang, Dongcheng and Daxing districts. A total of 131 questionnaires were issued and 131 questionnaires were received, including 122 valid questionnaires.

\section{CURRENT SITUATION OF ELECTRIC VEHICLES ' TIME - SHARING LEASING}

\section{A. Analysis on Current Situation of Vehicles}

Judging from the key factors of the selection of the new energy vehicle in Beijing, the time-sharing rental users in Beijing pay more attention to the endurance mileage and the convenience of charging, accounting for $43 \%$ and $22 \%$ respectively (Figure 1), which is related to the current performance and technology of new energy vehicle batteries and the construction of charging infrastructure.

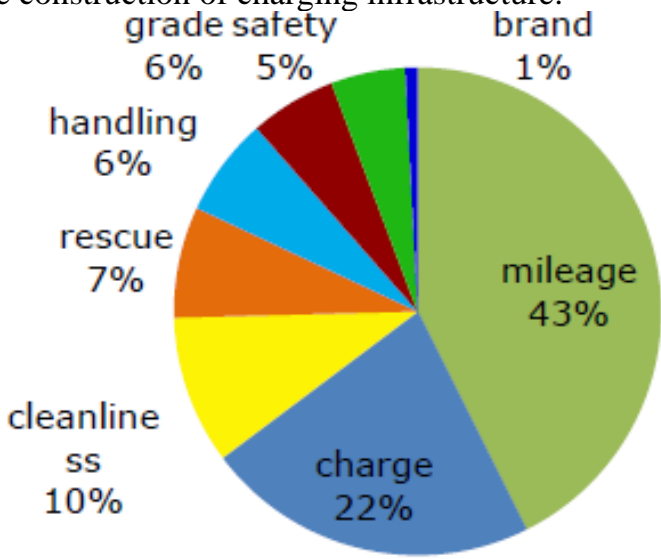

Figure 1. Key factors influencing the selection
According to the statistics of the preference of new energy vehicles for charging and switching modes, there are 61 time-sharing leasing users prefer wireless charging, as shown in figure 2. The user's preference for wireless charging is consistent with the results of the key factors that the user chooses to select the vehicle.

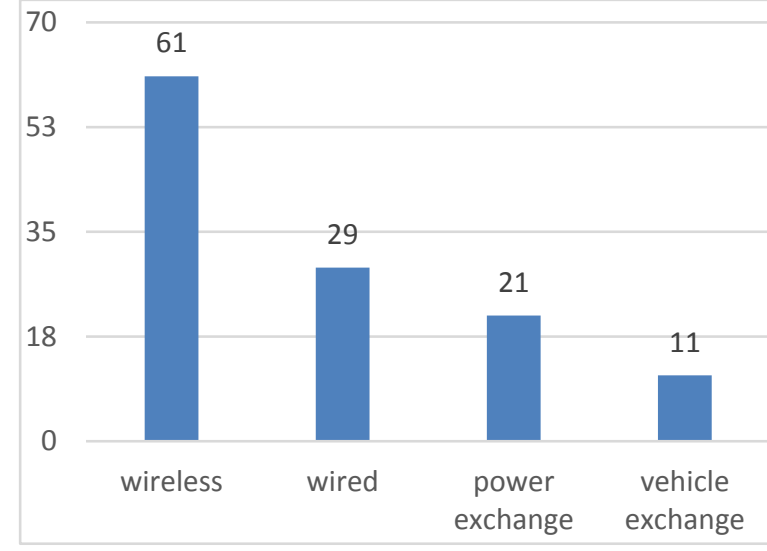

Figure 2. The form preference of charging

\section{B. Analysis of the Current Situation of Operation}

As the country's support for new energy vehicles increases, the existing leasing operators are mainly divided into state-owned car enterprises leading, private car enterprises leading, energy companies leading, leasing operators leading and internet enterprise leading. Survey data on the user's form of leasing companies for new energy vehicles show that leasing companies of state-owned car enterprises leading are more popular, accounting for $35 \%$ (Figure 3).

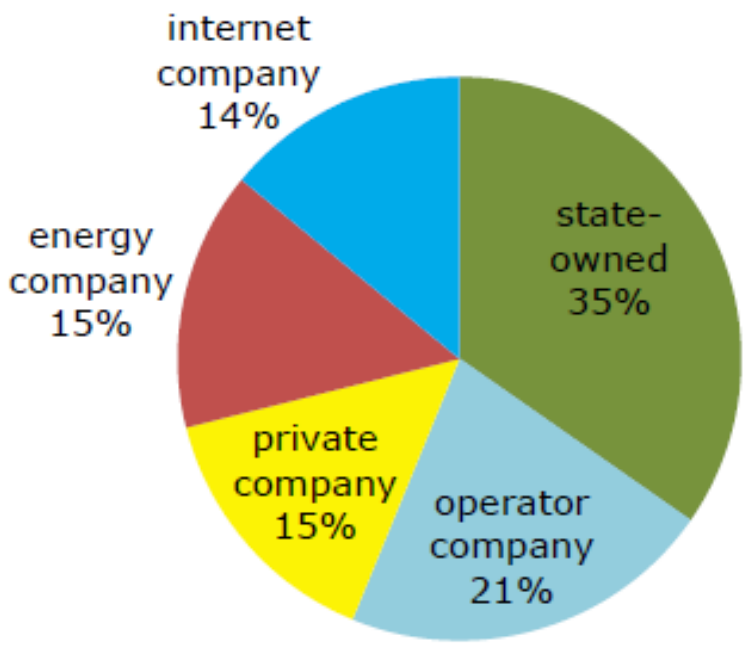

Figure 3. Forms of new energy vehicle leasing company

\section{Analysis on The Current Situation of Trading Mode}

The trading mode is the way in which time-sharing 
leasing enterprises can create wealth through various income flux under the control of cost, including: charging methods, revenue sources and cost structures. The mature trading mode is able to coordinate the network relationship of the various stakeholder.

According to the survey data of the users of new energy vehicles' time-sharing in Beijing, the perceived difference of the user's charging mode is not obvious (as shown in Figure 4). The proportion of the choice for available fees, fixed proportion of fees and leasing margin is basically the same, which is about $33 \%$.In terms of cost, $39 \%$ of users believe that the cost of time-sharing leasing operators is infrastructure construction; In terms of the source of income, $45 \%$ of users believe that the income of operators is mainly from the income of new energy vehicles' leasing 。

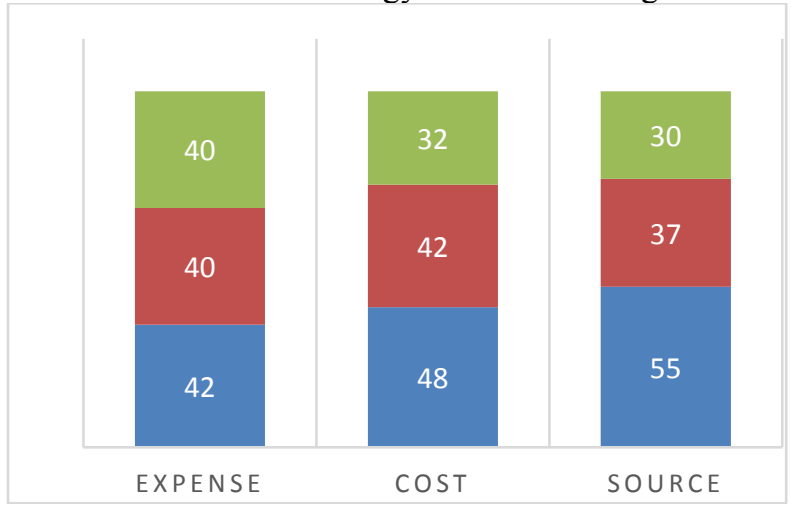

Figure 4. current situation of trading mode

\section{SUGGESTIONS}

Strengthen the support of government. The government should provide policy support from operating license, parking spaces and other aspects, reduce the costs of site acquisition of time-sharing rental enterprises and the using costs of consumers and reduce the operator's financial pressure, so that the electric vehicles' time-sharing leasing can provide lasting and effective support and encouragement. Strengthen the guidance of government. The government should guide from the level of urban planning, taking the electric car time-sharing leasing into the mode similar to a bus, rental, bicycle travel to plan, do a good job of forecast of time-sharing leasing scale and the guiding of network distribution and reserve location for urban construction and travel planning.

Combining second-hand car, refueling, parking and other concessions and time-sharing leasing, combining the commercial core group of parking or driving difficulty and the time-sharing leasing and increase the groups of users. Integrating the social idle vehicle to replace the purchase vehicle as far as possible, reduce the fund occupancy of the time-sharing leasing system, and speed up the expansion of the time-sharing rental network.

We should strengthen the cooperation with environmental protection departments and public welfare organizations from the perspective of changing consumers ' ideas and cognition, conduct vigorous propaganda by making use of advertising, media, lectures and other forms. In the early stage of operation, it needs a period of time for consumers to change their cognition and consumption concept. During this period, group purchase experience for free and other methods can be adopted to attract consumers and allow consumers to gradually accept the way of travel of electric vehicles' time-sharing leasing. Offer a more favorable price combination for enterprise users.

\section{V.CONCLUSION}

This article will take consumers of the electric vehicle time-sharing leasing as the research objects, carry out the research interview to the electric vehicle time-sharing leasing in Beijing area to understand the basic status of time-sharing leasing of electric vehicles in Beijing and to analyze the existing problems from the consumer point of view and put forward the corresponding solutions. Specific conclusions are as follows:

(1) Taking the Beijing market as an example, based on the data of on-the-spot investigation, interview and questionnaire, this paper makes a survey of typical time sharing modes of electric vehicles' leasing in Beijing from the point of view of factors in business models. The paper systematically analyzes the basic situation of time-sharing leasing in Beijing from three aspects of vehicle, operation mode and trading mode.

(2)From a practical point of view, the new energy vehicle time-sharing leasing has a stronger service innovation compared with car rental, conforming to the background of the Internet + . It is more flexible for consumers to use APPs in mobile phones to rent a car than renting a car in ordinary sites. The construction of the leasing sites reduces land occupation and capital investment, and enhances the advantages of time-sharing leasing mode.

(3)From the theoretical point of view, revenue model innovation of the new energy vehicle time-sharing leasing provides a differentiated service. Unlike online hailed car and public transport, consumers are unusually enthusiastic about green and flexible new energy vehicles.

\section{REFERENCE}

[1] Ji Xuehong, Xian Wenwen. Research on the profit model of electric vehicles' time-sharing leasing [J]. Automobile and accessories, 2015(50):39-41

[2] Liu Yingqi, Wang Jingyu, Ari Kokko. Policy and business model innovation of electric vehicle demonstration operations: global experience and China's practice $[\mathrm{J}]$. Soft Science in China, 2014,12(12)

[3] Wang Mingquan. Study on the feasibility of sharing and promotion of pure electric vehicles [J]. Traffic and transportation.2013.145-147.

[4] Chen Rongzhang, Yuanhao. Research on electric vehicles' leasing model and analysis of its feasibility [J]. Baic Motor, 2014(2):32-43 
[5] Ding Xiaohua, Wangmian, Chenyan, Zhang Yingjie, Zhang Wenjie, The development of business model of electric vehicles' sharing [J]. Science \& Technology Review, 2016 (6): 105-110.

[6] Xueyue, Yang Tongyu, Wen Sunbin. An analysis of the development model and social economic characteristics of vehicles sharing consumption $[\mathrm{J}]$. Technical economy and management research, 2008 156(1):54-58.

[7] Sun Chenxun, Li Hongyan, Li Runqin, Wnagxu. Application of analytic hierarchy process in comprehensive evaluation of management level [J]. Industrial technology economy, 2013, (09):7278 .

[8] Dengxue, Li Jiaming, Zeng Haojian, Chen Junyang, Zhao Junfeng. Analysis of weight calculation method of analytic hierarchy process and the research on its application [J]. Practice and understanding of mathematics, 2012, (07):93-100.

[9] Guo Jinyu, Zhang Zhongbin, Sun Qingyun. Research and application of analytic hierarchy process [J]. China Safety Science Journal, 2008, (05):148-153.

[10] SHAHEEN, S. A. \& COHEN, A. P. Carsharing and Personal Vehicle Services: Worldwide Market Developments and Emerging Trends[J].International Journal of Sustainable Transportation, 2013, Vol. 7 No. 1 , pp. $5-34$ 